\title{
Knowledge and practices of brucellosis among high-risk groups in Bahr El Ghazal Region, South Sudan
}

\author{
Nuol Aywel Madut ${ }^{1,2}$, George William Nasinyama ${ }^{2}$, John Bwalya Muma ${ }^{3}$, Adrian Muwonge ${ }^{4}$, James Muleme ${ }^{2}, J_{a c q u e s}$ Godfroid $^{5}$, Ambrose \\ Samuel Jubara ${ }^{1}$ and Clovice Kankya ${ }^{2 *}$ \\ ${ }^{1}$ Department of Clinical Studies, Faculty of Veterinary Science, University of Bahr el Ghazal, Wau, South Sudan \\ ${ }^{2}$ Department of Biosecurity, Ecosystems \&Veterinary Public Health (BEP), College of Vet. Animal Resources \& Biosecurity (COVAB). Makerere University, \\ Kampala, Uganda \\ ${ }^{3}$ Department of Disease Control, School of Veterinary Medicine, University of Zambia, Lusaka Zambia \\ ${ }^{4}$ Department of Genetics and Genomics, The Roslin Institute, University of Edinburgh, UK \\ ${ }^{5}$ Department of food Safety and infection Biology, Norwegian School of Veterinary Science, Troms, Norway
}

\begin{abstract}
Background: Brucellosis is the most common zoonotic infections in pastoral settings. Lack of knowledge about the disease may cause devastating out come to the patients, thus sustained it in such communities. This study assessed knowledge and practices among high-risk groups in Bahr el Ghazal region, South Sudan.

Methods: Across sectional survey involving abattoir workers, febrile patients at Wau referral hospital and cattle herders from cattle camps from four states namely, Wau, Tonj, Gogrial and Aweil. By using open-ended questionnaire and key informant guideline, for triangulations by for interviews, focus group discussions and key informant interview. Data collected include knowledge on causes, symptoms, transmission, treatment, prevention and risk factors of brucellosis. Using SPSS version 24 for analysis, $\mathrm{X}^{2}$ and Multivariable logistic regression analysis was performed.

Results: In this study, 234, 416 and 87 abattoir workers, febrile patients and herders. Brucellosis prevalence is fair among abattoir workers and the febrile patients, all workers Knows Brucellosis and Tuberculosis more than other diseases. Brucellosis among febrile patients, female more than male's respondents 23.7\% (50/416), $22.9 \%$ (47/234/416) respectively, the prevalence is very high among age group 16 to 35 . The disease was very high among non-educated people $25.4 \%$ (35/416). Nilotic group have high prevalence $21.8 \%$ (39/416), according to C-ELISA. In the cattle camps brucellosis prevalence among males was high than females $44.0 \%$ and $29.0 \%$ respectively. The prevalence was high among age groups $16-35$ years and 36-60years, $32.7 \%$ and 38.1 respectively, according to C- ELISA. The distribution of awareness of zoonotic diseases and brucellosis among abattoir workers, knowing zoonotic diseases 33.3\% (30/90), knowing brucellosis 27.8\% (25/90), knowing transmission of brucellosis $11.11 \%(10 / 25)$, however, knowledge of causes, signs of brucellosis in animals and signs human mode of transmission and treatment of brucellosis is very low.
\end{abstract}

Conclusions: Brucellosis prevalence is fair among abattoir workers, febrile patients and high in the cattle camps. All workers Knows Brucellosis and Tuberculosis more than other diseases.in the community the prevalence look equally between gender, knowledge about the diseases causes, signs in human and animal also mode of transmission and treatment was very low between the three groups. Community sensitization and awareness about zoonotic diseases is needed.

Abbreviations: C-ELISA: Competitive Enzyme-Linked Immuno sorbent Assay; RBPT: Rose Bengal Plate Agglutination Test; CI Confidence Interval.

\section{Introduction}

Brucellosis is an infectious bacterial disease of animal origin, circulating among animals and can be transmitted to those who live in closed proximity with their animals [1]. Brucellosis brings reproductive failure to livestock and serious health problems to humans [2,3]. It's described as neglected zoonotic disease in malaria endemic areas [4]. In many countries, zoonotic diseases are not considered as important simply because the diagnostic capacity to detect them hardly exists and equally important the focus of the clinician on the patients, not on their surroundings limited their diagnosis [5]. Where Lack of awareness the disease affects human health and as the result economic implications on animal production sector [6].

Brucellosis has been eradicated from developed countries, however it remains endemic in many parts of the developing world, including
Latin America, parts of the middle east, Western Asia, some countries in the Mediterranean basin, and Africa [7]. In sub-Saharan Africa, clinicians attribute most fever to malaria, even though an estimated $50-80 \%$ of fevers result from other causes [5]. e g. rift valley fever, bird flu and Yellow fever among others may be mixed with malaria fever, which called malaria like disease including Brucellosis [8]. Many countries look at the prevention and control of zoonotic diseases as very expensive so been deleted from the priorities. Consequently, some of governments often neglect zoonotic diseases, main while

Correspondence to: Dr. Clovice Kankya, Associate Professor, Head of Department of Biosecurity, Ecosystems and Veterinary Public Health, College of Vet. Animal Resources \& Biosecurity (COVAB). Makerere University, Kampala, Uganda, Tel: +256772545999; E-mail: clokankya@yahoo.com / clokankya@gmail.com

Key words: Brucellosis prevalence, Knowledge and practices of Brucellosis, high risk groups, Bahr el Ghazal region, South Sudan

Received: July 14, 2017; Accepted: August 01, 2017; Published: August 03, 2017 
other countries create ad hoc task forces between the concerned ministries of agriculture, livestock and health to tackle these diseases like the taskforce in Ethiopia for one health [9]. Such cooperation between sectors will be of great benefits to all sectors. Dissemination of Information between medics and veterinarians about zoonotic diseases especially in rural areas would be of great value, especially where limited laboratory capacity and infrastructure, infrastructures can easily be share between sectors. Other zoonotic diseases like Q-fever, anthrax and rabies in Wildlife would benefit from such cooperation and interlinings between sectors in line with domestic animal's disease control [10].

Knowledge about zoonotic diseases among communities would be better used for community based surveillance, risk analysis, prevention and integrated control for diseases [11]. The fight against Brucellosis as an example of zoonotic disease will provide valuable insights into current practices and serve as guiding tool for set good strategies for prevention and control of malaria and malaria like diseases in the study area and the whole country. The objectives of this study are to determine the awareness levels on brucellosis specifically on causes, symptoms, prevention, and treatment, to explore the perceptions of the communities on Brucellosis particularly in relation to causes, signs and symptoms, prevention, and treatment and to assess attitudes and practices towards Brucellosis.

\section{Materials and methods}

\section{Study area and population}

Qualitative information gathered for this study was obtained through application of questionnaire and interviews among slaughterhouses, and febrile patients in Wau hospital then in the cattle camps to compere and assess the awareness among these groups.

The survey sample comprised abattoir's worker, household's heads, Focus group discussions and key informant in the four states. Purposive selection method was employed. The FGD was selected based on group homogeneity such as occupation, and owning cattle. The group size about 6-8 individuals and discussion were done verbatim with use of both tape recorders and taking notes in the same time. Two transcriptionists were involved in data processing, transcription and entry, respectively.

\section{Study design and sampling procedure}

The study is community cross sectional study, based on work in the abattoirs and with the medical colleges in the hospitals all over the region, on the knowledge on brucellosis causes, transmission, and major symptoms of the disease.

\section{Study design and data collection}

The survey sample comprised abattoir's worker $(n=234)$, febrile patients in the hospital $(n=416)$, and household's heads $(n=40)$. And 8 focus group discussions and 8 key informants from veterinary officers, medical professionals and General directors from veterinary and health ministries in four selected states. Purposive selection method was employed. The FGD was selected based on group homogeneity such as occupation, and owning cattle. The group size about 6-8 individuals and discussion were done verbatim with use of both tape recorders and taking notes in the same time. Two transcriptionists were involved in data processing, transcription and entry, respectively.

\section{Data analysis}

The analysis was performed using SPSS var. 24 software. All focus group transcripts were serving as code. Then questions and node were aggregated across all of the focus groups, and the aggregated responses analyzed and summarized to describe similarities and differences in answers to each question across all of the groups.

\section{Ethical issues}

This study involves an administration of questionnaire and blood samples collection. Therefore, the study protocol was assessed and approved by the Ethical Review Committee of the College of Veterinary Medicine, Animal Resources and Biosecurity (COVAB), Makerere University, Uganda and both ministries health $(\mathrm{MOH})$ and Livestock and Fisheries Industry (MLFI), South Sudan respectively. Participant's consents were obtained prior to the start of interviews and data collection.

\section{Results}

In this study, 234 abattoir workers from four areas, 416 febrile patients from Wau referral hospital and 87 herders also included and 28FGD and at last we interviewed 12 veterinary and health officers to confirm and verified the information. The work conducted by team consists of medics and vets along with health workers. Sociodemographic characteristics Table 1.

According to the results from Tables 1, and figures 1; brucellosis is fair among abattoir workers and the febrile patients from Wau referral hospital.

Consumption of raw milk, meat, and other factors $\mathrm{P}>0.05$ Table 2 .

Brucellosis among febrile patients, female more than male's respondents $23.7 \%(50 / 416), 22.9 \%(47 / 234 / 416)$ respectively, the prevalence is very high among age group 16 to 35 . The disease was very high among non-educated people25.4\% (35/416), students have high prevalence $20.8 \%(25 / 416)$. Nilotic group have high prevalence $21.8 \%$ (39/416), according to C-ELISA Table 3.

Also this group knows Brucellosis and Tuberculosis more than other zoonotic diseases figure 2 below.

All factors like consumption of raw milk, meat, and using urine found were not significant $\mathrm{P}<0.05$ Table 4 .

In the cattle camps brucellosis prevalence among males was high than females $44.0 \%$ and $29.0 \%$ respectively. The prevalence was high among age groups 16- 35 years and 36- 60years, $32.7 \%$ and 38.1 respectively, according to C- ELISA Table 5.

Table 6 below showing the knowledge of brucellosis and zoonotic diseases is very poor.

\section{Awareness of causes, signs, symptoms and ways of transmission of brucellosis}

The distribution of awareness of zoonotic diseases and brucellosis among abattoir workers as follows, knowing zoonotic diseases 33.3\%(30/90), knowing brucellosis 27.8\% (25/90), knowing transmission of brucellosis $11.11 \%(10 / 25)$, no one knows the cause of brucellosis, knowing the signs of brucellosis in animals $11.11 \%$ $(10 / 25)$ and signs in human $27.8 \%$ (25/90), no one knows about mode of transmission and treatment of brucellosis table 7 .

\section{Discussion}

In this study we camper knowledge of brucellosis as zoonotic disease in term of causes, transmission, signs and prevention and control between three group namely abattoir workers, febrile patients 
Table 1. Brucellosis sero- prevalence against the demographics among abattoir workers December 2015-May 2016.

\begin{tabular}{|c|c|c|c|c|c|}
\hline Factor & Description & RBPT (\%) & c-Elisa (\%) & $X^{2}$ & P-Value \\
\hline \multirow{2}{*}{ Sex } & Female & $9(36)$ & $8(32)$ & $<0$ & 0.995 \\
\hline & Male & $89(42.6)$ & $67(32.1)$ & & \\
\hline \multirow{4}{*}{ Age } & $5-15$ & $1(25)$ & $1(25)$ & \multirow{4}{*}{6.231} & \multirow{4}{*}{0.101} \\
\hline & $16-35$ & $61(40.4)$ & $42(27.8)$ & & \\
\hline & $36-60$ & $33(44)$ & $29(38.7)$ & & \\
\hline & $>60$ & $3(75)$ & $3(75)$ & & \\
\hline \multirow{5}{*}{ Education } & Illiterate & $39(38.2)$ & $33(32.4)$ & \multirow{5}{*}{3.898} & \multirow{5}{*}{0.420} \\
\hline & $\begin{array}{l}\text { Higher } \\
\text { Education }\end{array}$ & $4(33.3)$ & $3(25)$ & & \\
\hline & Intermediate & $3(75)$ & $3(75)$ & & \\
\hline & Primary & $43(45.7)$ & $30(31.9)$ & & \\
\hline & Secondary & $9(40.9)$ & $6(27.3)$ & & \\
\hline \multirow{10}{*}{ Occupation } & Vet assistant & $12(57.1)$ & $10(47.6)$ & \multirow{9}{*}{18.516} & \multirow{9}{*}{$0.010^{*}$} \\
\hline & Butcher & $45(47.9)$ & $34(36.2)$ & & \\
\hline & $\begin{array}{l}\text { Health } \\
\text { worker }\end{array}$ & $9(64.3)$ & $5(35.7)$ & & \\
\hline & Meat handler & $25(43.9)$ & $21(36.8)$ & & \\
\hline & Administrator & $2(50)$ & $2(50)$ & & \\
\hline & $\begin{array}{l}\text { Casual } \\
\text { worker }\end{array}$ & $3(27.3)$ & $2(18.2)$ & & \\
\hline & $\begin{array}{l}\text { Cooks (Tea/ } \\
\text { food) }\end{array}$ & $1(4)$ & 0 & & \\
\hline & Cattle trader & $1(12.5)$ & $1(12.5)$ & & \\
\hline & Others & 0 & 0 & & \\
\hline & Total & 98 (41.9) & $75(32.1)$ & & \\
\hline
\end{tabular}

Table 2. Multivariate logistic regression model (of the known risk factor variables).

\begin{tabular}{|c|c|c|c|}
\hline \multicolumn{3}{|c|}{ Risk factors } \\
\hline \multicolumn{3}{|c|}{ OR-value } & $\mathbf{9 5 \%}$ CI \\
\hline Consumes raw meat & 1.382 & 0.309 & $0.740-2.582$ \\
\hline Consumes raw milk & 1.036 & 0.916 & $0.536-2.002$ \\
\hline Consumes urine from animals & 1.066 & 0.873 & $0.484-2.349$ \\
\hline Has hand abrasions & 0.791 & 0.467 & $0.421-1.487$ \\
\hline Wash hands after work & 0.599 & 0.227 & $0.261-1.376$ \\
\hline
\end{tabular}

admitted to Wau referral hospital outpatient clinic and animal's herders in the cattle camps from Bahr El Ghazal region. The study recruit 234-abattoir workers, 416 febrile patients, and 87 individual represent house holed from cattle camps from Tonj and Aweil states. Brucellosis prevalence between these groups was $32.1 \%(75 / 234)$, $23.3 \%(97 / 416)$ and $33.3 \%(29 / 87)$ for abattoir workers, febrile patients and cattle herders respectively, according to C- ELISA.

This study, also include 28FGD and interviewed 12 veterinary and health officers to confirm and verified the information.

Sudan is one of the malaria endemic areas in Sub-Saharan African, also there are many malaria like diseases endemic in Sudan, brucellosis is one of these group of diseases endemic in Sudan. This group of malaria like diseases always underreported and misdiagnosed in Sudan and many other countries in Africa especially in Sub- Saharan Africa due to lack of basic infrastructures facilities, diagnostic materials and well-trained personnel to perform the diagnosis [5]. Most of the time the diagnostic facilities if available were to far to reach by the nomads and cattle herders. Also there were many traditional behaviors and perceptions among animal's keeps may expose them to be infected by one of this malaria like diseases. Brucellosis is the most zoonotic disease widely distributed among animal's keeping communities due to food intake behaviors like consumption of unpasteurized milk, eating raw meat and offal's, and poor hygiene in the cattle camps, abattoirs and in the houses especially when they deal with animals and animal's products [12]. In South Sudan, people depend on livestock for their livelihood, also Livestock play essential role in their social life. However, this attitude exposed them to many zoonotic diseases as well as to brucellosis. Animal herders in all parts of South Sudan are at risk of exposure to brucellosis due to they live close proximity with their animals in cattle camps and drink raw milk, assess animals on delivery and in some cases treat retained placenta with their pear hands without any protection [13]. No serological and microscopic diagnosis is preform in most health clinics for brucellosis especially in pastoral areas, moreover no any control strategy to tackle the disease in the country due to the devastating situation created by the long civil war. Lack of awareness about brucellosis among abattoir workers, animal's herders and the whole community. As a consequence brucellosis remains a largely neglected disease with little attention given to control and prevention. In addition, the effect of brucellosis on human health in Southern Sudan is unknown [14].

Knowledge of brucellosis among abattoir workers and febrile patients admitted to Wau referral hospital in the Bahr el Ghazal region is fair, however the knowledge of the disease among herders in cattle camps is poor this results inline with [15] and this results contradict the results obtained by A Catley, et al. [16] that could be attributed to poor education, poor hygiene measures adopted in the camps and also the consumption of raw milk and it is raw products like soar milk. Also in addition to this their activities in the cattle camps like milking, assess animals on delivery and retained placenta and spreading dungs with pear hands could be one of the factors.

In South Sudan many factors could make transmission of brucellosis between livestock and humans. The practice of assembling animals into one big cattle camp with close livestock- human interaction is one of the key factors.

(Most of the cattle herders in the region prefer to keep infected animals within the herd without slaughtering or selling. Moreover, there were many signs of the disease among animals like hygroma, abortions and retained placenta that could be attributed to their traditions and norms of keeping large herds even if diseases were there), (DG Wau vet. hospital).

(Mixing infected animals and healthy one in the pastors and in the camp closely means that spreading of diseases very easy among and between herds). (vet. Officer).

Moreover, poor awareness among herders could be a risk of brucellosis. Further, animal herder's practice of vulva blowing, to facilitate milk let down during cow milking and udder- to -mouth consumption of milk could exacerbate human brucellosis.

(Sometimes herders share their bulls for purpose of insemination could be one of the means of spreading the disease. In Bahr el Ghazal region every year herders migrate looking for water and pastors, this could bring herds in contact with other herds or wildife animals and that could maintain the presence of the disease in the region), (DG Wau vet.hospital).

Bahr El Ghazal region annually host transhumance from other countries could be source of infection among herds.

(Transhumance herds like Fulani red Mbororo and cattle herds from northern Sudan also could be a reason for spreading the disease among herds. Moreover, in South Sudan there is no implementation of control strategy for competing the disease. All in all brucellosis is endemic in 
Table 3. Demographic characteristics Brucellosis Sero- prevalence among febrile patients December 2015 -May 2016.

\begin{tabular}{|c|c|c|c|c|c|c|}
\hline Factor & N (\%) & RBPT (\%) & SAT (\%) & cElisa (\%) & $X^{2}$ & P-Value \\
\hline \multicolumn{7}{|c|}{ Sex } \\
\hline Female & $211(50.7)$ & $138(65.4)$ & $87(41.2)$ & $50(23.7)$ & \multirow{2}{*}{0.034} & \multirow{2}{*}{0.853} \\
\hline Male & $205(49.3)$ & $144(70.2)$ & $96(46.8)$ & $47(22.9)$ & & \\
\hline \multicolumn{7}{|c|}{ Age } \\
\hline $5-15$ & $26(6.2)$ & $20(76.9)$ & $14(53.8)$ & $5(19.2)$ & \multirow{4}{*}{48.130} & \multirow{4}{*}{0.764} \\
\hline $16-35$ & $272(65.4)$ & $185(68.0)$ & $119(43.8)$ & $62(22.8)$ & & \\
\hline $36-60$ & $107(25.7)$ & $71(66.4)$ & $46(43.0)$ & $29(27.1)$ & & \\
\hline$>60$ & $11(2.6)$ & $6(54.5)$ & $4(36.4)$ & $1(9.1)$ & & \\
\hline \multicolumn{7}{|c|}{ Education } \\
\hline Illiterate & $138(33.2)$ & $99(71.7)$ & $66(47.8)$ & $35(25.4)$ & \multirow{5}{*}{0.953} & \multirow{5}{*}{0.917} \\
\hline Higher Education & $66(15.9)$ & $44(66.7)$ & $23(34.8)$ & $14(21.2)$ & & \\
\hline Intermediate & $77(18.5)$ & $50(64.9)$ & $35(45.5)$ & $17(22.1)$ & & \\
\hline Primary & $72(17.3)$ & $46(63.9)$ & $30(41.7)$ & $15(20.8)$ & & \\
\hline Secondary & $63(15.1)$ & $43(68.3)$ & $29(46.0)$ & $16(25.4)$ & & \\
\hline \multicolumn{7}{|c|}{ Occupation } \\
\hline Butcher & $3(0.7)$ & $2(66.7)$ & $1(33.3)$ & $1(33.3)$ & \multirow{10}{*}{10.277} & \multirow{10}{*}{0.329} \\
\hline Business/Trader & $15(3.6)$ & $8(53.3)$ & $7(46.7)$ & $1(6.7)$ & & \\
\hline Nurse/Midwife & $4(1.0)$ & $1(25.0)$ & $1(25.0)$ & 0 & & \\
\hline House wife & $35(8.4)$ & $25(71.4)$ & $16(45.7)$ & $6(17.1)$ & & \\
\hline Student & $120(28.8)$ & $84(70.0$ & $50(41.7)$ & $25(20.8)$ & & \\
\hline Restaurant worker & $29(7.0)$ & $19(65.5)$ & $14(48.3)$ & $5(17.2)$ & & \\
\hline Veterinary Officer & $5(1.2)$ & $4(80.0)$ & $1(20.0)$ & $2(40.0)$ & & \\
\hline Farmer & $9(2.2)$ & $6(66.7)$ & $4(44.4)$ & $3(33.3)$ & & \\
\hline Jobless & $40(9.6)$ & $26(65.0)$ & $12(30.0)$ & $14(35.0)$ & & \\
\hline Others & $156(37.5)$ & $107(68.6)$ & $77(49.4)$ & $40(25.6)$ & & \\
\hline
\end{tabular}

\section{RESPONDENTS KNOWLEDGE ON ZONOTIC}

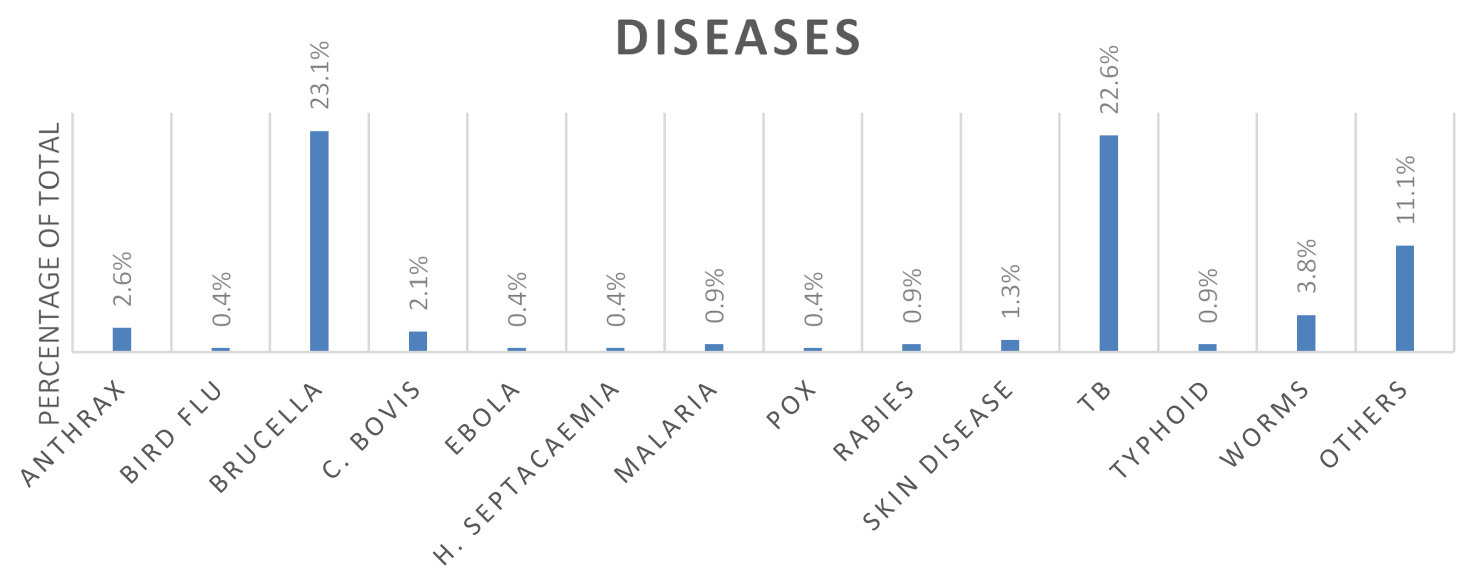

ZOONOTIC DISEASE

Figure 1. All workers Know Brucellosis and Tuberculosis more than other diseases.

this country from along time because of the open borders and the long war that bring animals from all over to one place. Other reasons no vaccination program for the disease in the country), (vet. officer).

Traditionally herders treat their animals without consultation from veterinary authority, and that could be one of the reasons behind early detection of the disease.
(I have veterinary pharmacy in the market and most of the time nomads come to my place asked about certain drugs without explaining the disease or signs that their animals suffered from), (vet. Officer).

Since the disease is endemic in the region from along time why the veterinary authority conduct surveillance and set prevention strategies for the disease. 


\section{Respondents knowledge on zoonotic diseases}

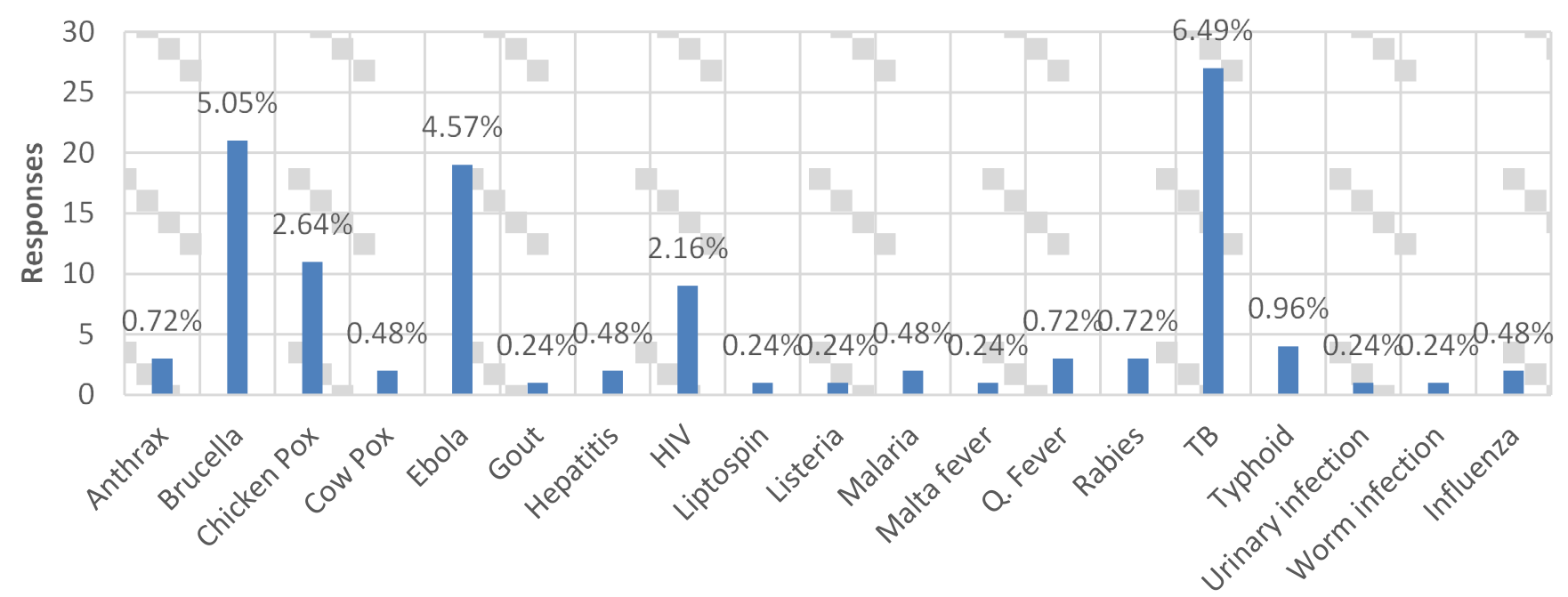

Zoonotic disease

Figure 2. Showing the respondents knowledge on zoonotic diseases.

Table 4. Multivariate Logistic Regression of risk factors for occurrence of Brucellosis among human participants.

\begin{tabular}{|c|c|c|c|}
\hline Risk factors & OR & p-value & 0.396 \\
\hline Consumes raw meat & 1.368 & $0.663-2.82$ & 0.722 \\
\hline Consumes raw milk & 1.124 & 0.056 & $0.589-2.146$ \\
\hline Consumes urine from animals & 2.552 & 0.183 & $0.978-6.66$ \\
\hline Has hand abrasions & 0.671 & 0.211 \\
\hline
\end{tabular}

Table 5. Demographic characteristics and brucellosis seropositive among herders in Bahr el Ghazal region December 2015-May 2016.

\begin{tabular}{|c|c|c|c|c|c|c|c|c|}
\hline \multirow{2}{*}{\multicolumn{2}{|c|}{ Variable/ description }} & \multicolumn{2}{|c|}{ RBPT } & \multicolumn{2}{|c|}{ SAT } & \multicolumn{2}{|c|}{ C-ELISA } & \multirow{3}{*}{\begin{tabular}{|c|} 
Total \\
25 \\
\end{tabular}} \\
\hline & & \multirow{2}{*}{$\begin{array}{c}\text { Negative } \\
48.0 \%(12)\end{array}$} & \multirow{2}{*}{$\begin{array}{c}\text { Positive } \\
52.0 \%(13)\end{array}$} & \multirow{2}{*}{$\begin{array}{c}\text { Negative } \\
44.0 \%(11)\end{array}$} & \multirow{2}{*}{$\begin{array}{c}\text { Positive } \\
56.0 \%(14)\end{array}$} & \multirow{2}{*}{$\begin{array}{c}\text { Negative } \\
56.0 \%(14)\end{array}$} & \multirow{2}{*}{$\begin{array}{c}\text { Positive } \\
44.0 \%(11)\end{array}$} & \\
\hline Cond & Male & & & & & & & \\
\hline Gender & Female & $64.5 \%(40)$ & $35.5 \%(22)$ & $59.7 \%(37)$ & $40.3 \%(25)$ & $71.0 \%(44)$ & $29.0 \%(18)$ & 62 \\
\hline \multirow{5}{*}{ Age Group } & $0-5$ & $100.0 \%(2)$ & $0.0 \%(0)$ & $100.0 \%(2)$ & $0.0 \%(0)$ & $100.0 \%(2)$ & $0.0 \%(0)$ & 2 \\
\hline & $6-15$ & $76.9 \%(10)$ & $23.1 \%(3)$ & $61.5 \%(8)$ & $38.5 \%(5)$ & $76.9 \%(10)$ & $23.1 \%(3)$ & 13 \\
\hline & $16-35$ & $57.1 \%(28)$ & $42.9 \%(21)$ & $55.1 \%(27)$ & $44.9 \%(22)$ & $67.3 \%(33)$ & $32.7 \%(16)$ & 49 \\
\hline & $36-60$ & $57.1 \%(12)$ & $42.9 \%(9)$ & $52.4 \%(11)$ & $47.6 \%(10)$ & $61.9 \%(13)$ & $38.1 \%(8)$ & 21 \\
\hline & $>61$ & $0.0 \%(0)$ & $100.0 \%(2)$ & $0.0 \%(0)$ & $100.0 \%(2)$ & $0.0 \%(0)$ & $100.0 \%(2)$ & 2 \\
\hline \multirow{2}{*}{ Occupation } & Farmer & $63.6 \%(21)$ & $36.4 \%(12)$ & $57.6 \%(19)$ & $42.4 \%(14)$ & $63.6 \%(21)$ & $36.4 \%(12)$ & 33 \\
\hline & Milking & $56.5 \%(26)$ & $43.5 \%(20)$ & $52.2 \%(24)$ & $47.8 \%(22)$ & $67.4 \%(31)$ & $32.6 \%(15)$ & 46 \\
\hline \multirow{2}{*}{ Education } & Illiterate & $57.8 \%(48)$ & $42.2 \%(35)$ & $53.0 \%(44)$ & $47.0 \%(39)$ & $65.1 \%(54)$ & $34.9 \%(29)$ & 83 \\
\hline & Literate & $100.0 \%(4)$ & $0.0 \%(0)$ & $100.0 \%$ & $0.0 \%(0)$ & $100.0 \%(4)$ & $0.0 \%(0)$ & 4 \\
\hline Total & & $59.8 \%(52)$ & $40.2 \%(35)$ & $55.2 \%(48)$ & $44.8 \%(39)$ & $66.7 \%(58)$ & $33.3 \%(29)$ & 87 \\
\hline
\end{tabular}

Table 6. Below showing the knowledge of brucellosis and zoonotic diseases is very poor.

\begin{tabular}{|c|c|c|c|c|c|c|c|c|}
\hline \multirow[b]{2}{*}{ Factors } & \multirow[b]{2}{*}{ Responds } & \multicolumn{2}{|c|}{ RBPT } & \multicolumn{2}{|c|}{ SAT } & \multicolumn{2}{|c|}{ C-ELISA } & \multirow[b]{2}{*}{ Total } \\
\hline & & Negative & Positive & Negative & Positive & Negative & Positive & \\
\hline \multirow{2}{*}{$\begin{array}{l}\text { Zoonotic diseases } \\
\text { Awareness }\end{array}$} & No & $59.8 \%(52)$ & $40.2 \%(35)$ & $55.2 \%(48)$ & $44.8 \%(39)$ & $66.7 \%(58)$ & $33.3 \%(29)$ & 87 \\
\hline & Yes & $0.0 \%(0)$ & $0.0 \%(0)$ & $0.0 \%(0)$ & $0.0 \%(0)$ & $0.0 \%(0)$ & $0.0 \%(0)$ & 0 \\
\hline \multirow{2}{*}{ Aware of brucella } & No & $59.8 \%(52)$ & $40.2 \%(35$ & $55.2 \%(48)$ & $44.8 \%(39)$ & $66.7 \%(58)$ & $33.3 \%(29)$ & 87 \\
\hline & Yes & $0.0 \%(0)$ & $0.0 \%(0)$ & $0.0 \%(0)$ & $0.0 \%(0)$ & $0.0 \%(0)$ & $0.0 \%(0)$ & 0 \\
\hline \multirow{2}{*}{ Animal signs } & No & $59.8 \%(52)$ & $40.2 \%(35$ & $55.2 \%(48)$ & $44.8 \%(39)$ & $66.7 \%(58)$ & $33.3 \%(29)$ & 87 \\
\hline & Yes & $0.0 \%(0)$ & $0.0 \%(0)$ & $0.0 \%(0)$ & $0.0 \%(0)$ & $0.0 \%(0)$ & $0.0 \%(0)$ & 0 \\
\hline \multirow{2}{*}{ Human signs } & No & $59.8 \%(52)$ & $40.2 \%(35$ & $55.2 \%(48)$ & $44.8 \%(39)$ & $66.7 \%(58)$ & $33.3 \%(29)$ & 87 \\
\hline & Yes & $0.0 \%(0)$ & $0.0 \%(0)$ & $0.0 \%(0)$ & $0.0 \%(0)$ & $0.0 \%(0)$ & $0.0 \%(0)$ & 0 \\
\hline
\end{tabular}


Table 7. Awareness among abattoir workers \& febrile patients from the hospital.

\begin{tabular}{|c|c|c|c|c|c|c|}
\hline \multicolumn{4}{|c|}{ Abattoir workers } & \multicolumn{3}{|c|}{ Febrile patients } \\
\hline Question & Response among herders & Number of respondent & Responders \% & Response among herders & Number of respondent & Responders \% \\
\hline \multirow{2}{*}{$\begin{array}{l}\text { Have you heard about } \\
\text { zoonotic diseases? }\end{array}$} & Yes & 83 & $35.5 \%$ & Yes & 371 & $89.2 \%$ \\
\hline & No & 151 & $64.5 \%$ & No & 45 & $10.8 \%$ \\
\hline \multirow{2}{*}{$\begin{array}{l}\text { Have you heard } \\
\text { about disease called } \\
\text { Brucellosis? }\end{array}$} & Yes & 25 & $30.1 \%$ & Yes & 221 & $59.6 \%$ \\
\hline & No & 58 & $69.9 \%$ & No & 150 & $40.4 \%$ \\
\hline \multirow{2}{*}{$\begin{array}{l}\text { If yes, do you know how } \\
\text { its spread? }\end{array}$} & Yes & 10 & $11.11 \%$ & Yes & 221 & $59.6 \%$ \\
\hline & No & 15 & $16.7 \%$ & No & 150 & $40.4 \%$ \\
\hline \multirow{2}{*}{ Do you know the cause? } & Yes & 0 & 00.00 & Yes & 221 & $59.6 \%$ \\
\hline & No & 25 & $100 \%$ & No & 150 & $40.4 \%$ \\
\hline \multirow{2}{*}{$\begin{array}{c}\text { Do you know the signs in } \\
\text { animals? }\end{array}$} & Yes & 10 & $11.11 \%$ & Yes & 221 & $59.6 \%$ \\
\hline & No & 15 & $16.7 \%$ & No & 150 & $40.4 \%$ \\
\hline \multirow{2}{*}{$\begin{array}{c}\text { Are you aware that } \\
\text { brucellosis infects } \\
\text { human? }\end{array}$} & Yes & 25 & $27.8 \%$ & Yes & 221 & $59.6 \%$ \\
\hline & No & 65 & $72.2 \%$ & No & 150 & $40.4 \%$ \\
\hline \multirow{2}{*}{$\begin{array}{l}\text { If yes, do you know the } \\
\text { signs in human? }\end{array}$} & Yes & 0 & 00.00 & Yes & 221 & $59.6 \%$ \\
\hline & No & 25 & $100 \%$ & No & 150 & $40.4 \%$ \\
\hline \multirow{2}{*}{$\begin{array}{l}\text { Do you aware of the } \\
\text { mode of transmission? }\end{array}$} & Yes & 0 & 00.00 & Yes & 221 & $59.6 \%$ \\
\hline & No & 25 & $100 \%$ & No & 150 & $40.4 \%$ \\
\hline \multirow{2}{*}{$\begin{array}{l}\text { Do you know the } \\
\text { treatment? }\end{array}$} & Yes & 0 & 00.00 & Yes & 221 & $59.6 \%$ \\
\hline & No & 25 & $100 \%$ & No & 150 & $40.4 \%$ \\
\hline
\end{tabular}

(The herders them self their revenues from the herds are very limited and their herds for social status not for economic benefits), (DG Wau vet.hospital).

(The way out for the national herds is to educate these communities about the correct way of keeping animals and motivate them to adopt selling and buying animals instead of keeping animals without economic significant), (DG Wau vet.hospital).

For the government, the national herds contribute about $15 \%$ from the total GDP of the country, and also the herders are not co-operative in this issue, so the government counts on oil revenue mostly.

(We conduct vaccination campaigns annually before the dry season for vaccinate for $B Q$, Anthrax, CBBP and HS however brucellosis not included),(DG Wau vet.hospital).

(Actually brucellosis vaccination since we are one country with Sudan not included in the vaccination campaigns, every farmer vaccinates alone his herd, and moreover the disease some time appears in veterinarians and their assistance), (DG Wau vet.hospital).

\section{Conclusion}

This study reveals that a large proportion of high-risk groups (abattoir workers, febrile patients) having broad Knowledge of brucellosis. Knowledge of the disease causes, signs, and mode of transmission were very poor. Living in close proximity with their animals, sharing water source with animals and poor hygiene in their environment were identified as possible transmission routes for the disease. Consumption of untreated milk and meat were perceived to be exposed routes for acquiring the disease among pastoralists. Diseases management by the herders themselves or traditional healers could transform the animal into carrier stage. Therefore, there is need to strengthen public awareness about zoonotic diseases and implements prevention and control for brucellosis by the authorities.

\section{Competing interests}

The authors declare that they have no competing interests.

\section{Authors' contributions}

NM contributed to the design, data collection, drafting and writing of the manuscript. AM, GWN contributed to data analysis and drafting of the manuscript. AJ contributed to design, data analysis and drafting of the manuscript. CK, JBM contributed to conception, design, and drafting and writing of the manuscript. J G: contributed to the design, drafting and writing of the manuscript. JM contributed on drafting and editing the manuscript. All authors have read and approved the final manuscript.

\section{Acknowledgement}

The authors express their sincere gratitude for the financial support from the Norwegian program for development research and education (Norhed) and Makerere University Graduate School. Special thanks go to field research assistance from Mr. Samuel Julio Daba, Dr. Mohammed Adam and the slaughterhouses administrators in Wau, Tonj, Kuajok and Weil states.

\section{Ethical approval}

This study involves an administration of questionnaire and blood samples collection. Therefore, the study protocol was assessed and approved by the Ethical Review Committee of the College of Veterinary Medicine, Animal Resources and Biosecurity (COVAB), Makerere University, Uganda vide the reference number of SBLS/NA/2015 and ethical approved from both ministries health $(\mathrm{MOH})$ and Livestock and Fisheries Industry (MLFI), South Sudan respectively. Participant's consents were obtained prior to the start of interviews and data collection. Moreover, import and export permits of the biological samples were obtained from Ministry of Agriculture, Animal Industry and Fisheries (MAAIF) - LHE 46/172/406, Uganda and Ministry of Livestock and Fisheries Industry (MLFI), South Sudan - RSS/MLFI/ DVS/J/39, respectively, prior to shipment from and to designate country.

\section{References}

1. Refai M (2002) Incidence and control of brucellosis in the Near East region. Vet Microbiol 90: 81-110. [Crossref] 
2. Tsegay A, Tuli G, Kassa T, Kebede N (2015) Seroprevalence and risk factors of Brucellosis in small ruminants slaughtered at Debre Ziet and Modjo export abattoirs, Ethiopia. BMC Infect Dis 9: 373-380.

3. Otte J, Grace D (2012) Human health risks from the human-animal interface in Asia. Asian livestock 16: 121

4. WHO (2006) The control of neglected zoonotic diseases: a route to poverty alleviation: report of a joint world health organization.

5. McDermott JJ, Arimi SM (2002) Brucellosis in sub-Saharan Africa: epidemiology, control and impact. Vet Microbiol 90: 111-134. [Crossref]

6. Kansiime C, Mugisha A, Makumbi F, Mugisha S, Rwego IB, et al. (2014) Knowledge and perceptions of brucellosis in the pastoral communities adjacent to Lake Mburo National Park, Uganda. BMC Public Health 14: 242. [Crossref]

7. Godfroid J, Cloeckaert A, Liautard JP, Kohler S, Fretin D, et al. (2005) From the discovery of the Malta fever's agent to the discovery of a marine mammal reservoir, brucellosis has continuously been a re-emerging zoonosis. Veterinary research 36 : 313-326.

8. Crump JA, Morrissey AB, Nicholson WL, Massung RF, Stoddard RA, et al. (2013) Etiology of severe non-malaria febrile illness in Northern Tanzania: a prospective cohort study. PLoS Negl Trop Dis 7: e2324. [Crossref]

9. Wirth ME, Balk D, Delamonica E, Storeygard A, Sacks E, et al. (2006) Setting the stage for equity-sensitive monitoring of the maternal and child health Millennium Development Goals. Bull World Health Organ 84: 519-527.
10. Conti LA, Rabinowitz PM (2011) One health initiative will unite human and veterinary medicine. Infektološki Glasnik 31: 176-178.

11. Daumerie D, Savioli L (2010) Working to overcome the global impact of neglected tropical diseases: first WHO report on neglected tropical diseases, World Health Organization 1: 1-169.

12. Gaafar N, Ismaeel A, Elduma A, Saeed E, Hamid M (2013) Seroprevalence of Brucellosis among people in contact with livestock in suburban Khartoum, Sudan. Annals of Tropical Medicine and Public Health 6: 649.

13. Morton J, Kerven C (2013) Livelihoods and basic service support in the drylands of the Horn of Africa: Brief prepared by a Technical Consortium hosted by CGIAR in partnership with the FAO Investment Centre. CGSpace, CGIAR.

14. Lado D, Maina N, Lado M, Abade A, Amwayi S, et al. (2012) BRUCELLOSIS IN TEREKEKA COUNTY, CENTRAL EQUATORIA STATE, SOUTHERN SUDAN. East Afr Med J 89: 28-33. [Crossref]

15. Bollig M (1997) Risk and risk minimisation among Himba pastoralists in northwestern Namibia. Nomadic peoples pp. 66-89.

16. Catley A, Okoth S, Osman J, Fison T, Njiru Z, et al. (2001) Participatory diagnosis of a chronic wasting disease in cattle in southern Sudan. Preventive Veterinary Medicine 51: 161-181.

Copyright: (C2017 Madut NA. This is an open-access article distributed under the terms of the Creative Commons Attribution License, which permits unrestricted use, distribution, and reproduction in any medium, provided the original author and source are credited. 